\title{
Marcella Leopizzi, La sorcellerie dans les œuvres de Montaigne, de Vanini et de Naudé
}

\section{Dario Cecchetti}

\section{(2) OpenEdition}

1 Journals

\section{Edizione digitale}

URL: https://journals.openedition.org/studifrancesi/26168

DOI: 10.4000/studifrancesi.26168

ISSN: 2421-5856

\section{Editore}

Rosenberg \& Sellier

\section{Edizione cartacea}

Data di pubblicazione: 1 avril 2007

Paginazione: 168

ISSN: 0039-2944

\section{Notizia bibliografica digitale}

Dario Cecchetti, «Marcella Leopizzi, La sorcellerie dans les œuvres de Montaigne, de Vanini et de Naudé», Studi Francesi [Online], 151 (LI | I) | 2007, online dal 30 novembre 2015, consultato il 23 novembre 2021. URL: http://journals.openedition.org/studifrancesi/26168; DOI: https://doi.org/10.4000/ studifrancesi.26168

Questo documento è stato generato automaticamente il 23 novembre 2021.

\section{(c) $(1) \ominus$}

Studi Francesi è distribuita con Licenza Creative Commons Attribuzione - Non commerciale - Non opere derivate 4.0 Internazionale. 


\title{
Marcella Leopizzi, La sorcellerie dans les cuvres de Montaigne, de Vanini et de Naudé
}

\author{
Dario Cecchetti
}

\section{NOTIZIA}

MARCELla Leopizzi, La sorcellerie dans les cuvres de Montaigne, de Vanini et de Naudé, «Franco-Italica», n. 29-30, 2006, pp. 51-74.

M. Leopizzi, studiosa di Vanini, consacra un interessante studio al tema della stregoneria nelle opere di Montaigne, Vanini e Naudé, dei quali vengono messe in evidenza le analogie per quanto concerne la riflessione sul problema. In un momento, infatti, in cui in Europa è diffusa una vera e propria ossessione nei confronti della stregoneria, tutti e tre gli autori si dimostrano scettici riguardo ai fenomeni di possessione diabolica e formulano opinioni pressoché identiche nei confronti dei roghi per le streghe. Ora, come ben sottolinea l'A., Montaigne apparirebbe come il modello e l'ispiratore delle posizioni degli altri due pensatori libertini, nel demolire in nome della ragione le credenze nel magico demoniaco e nel sostituire delle spiegazioni d'ordine razionale, quali la suggestione o la malattia mentale. Il merito di M. Leopizzi è di percorrere non solo i testi ben conosciuti di Montaigne, ma anche quelli di Vanini e Naudé, di cui vengono minuziosamente evidenziate sia le intertestualità con l'archetipo montaignista sia le peculiarità, con la segnalazione anche di altri apporti concettuali, come quelli del padovano Cremonini. Per quanto, prudentemente, essa concluda ricordando che non tutti i critici accettano un rapporto diretto di Vanini e Naudé con Montaigne, l'A. offre un quadro convincente del gioco di intertestualità che vedono Montaigne punto di riferimento del libertinage della prima metà del Seicento. 